\title{
Antecedentes do desenho industrial na Argentina e no Brasil: constituição das mentalidades industriais e dependência tecnológica
}

\section{Background of industrial design in Argentina and Brazil: the constitution of industrial mentalities and technological dependence}

\author{
Patricia Amorim, ESPM-SP e FAU USP \\ pat.amorim@gmail.com
}

\section{Resumo}

A introdução do desenho industrial moderno no Brasil e na Argentina ocorreu nos anos 1950 num contexto de acentuada modernização econômica e cultural. Fomentado por incentivos estatais, esse foi um período de significativa industrialização que buscou mitigar o atraso tecnológico e fabril dessas nações historicamente fornecedoras de matérias-primas básicas aos mercados centrais. Nesse contexto, a lenta inserção de uma nova atividade profissional essencialmente vinculada à indústria deu-se no enfrentamento de desafios de várias ordens, os quais têm origem num passado muito anterior ao contexto do pós-Segunda Guerra. Este artigo, portanto, vai além das condicionantes imediatas, e traça um conciso panorama histórico-comparativo - do século $\mathrm{XVI}$ às primeiras décadas do século XX - esboçando o modo tortuoso no qual Argentina e Brasil elaboraram sua mentalidade industrial e empreendedora.

Palavras-chave: Desenho Industrial, Design Moderno, Artesanato, Brasil, Argentina

\begin{abstract}
The introduction of modern industrial design in Brazil and Argentina took place in the 1950s in a context of fierce economic and cultural modernization. Fostered by state incentives, this was a period of significant industrialization that sought to mitigate the technological and manufacturing backwardness of these nations, historically suppliers of primary raw materials to central markets. In this context, the slow insertion of a new professional activity inherently linked to the industry occurred in the face of challenges of various orders, which originate in a past much earlier than the post-World War II context. This article, therefore, goes beyond the immediate conditions and traces a concise historical-comparative panorama-from the 16th century to the first decades of the 20th century - outlining the tortuous way in which Argentina and Brazil developed their industrial and entrepreneurial mentality.
\end{abstract}

Keywords: Industrial design, Modern Design, Craftwork, Brazil, Argentina 


\section{Introdução}

O surgimento do design moderno e industrial como atividade profissional resulta das necessidades de melhoria dos aspectos estético-funcionais dos produtos manufaturados pelas indústrias da Inglaterra no século XIX (BRAGA, 2011). É na primeira metade do século XX, contudo, que se inicia a introdução, a prática e o desenvolvimento do design moderno em países como Brasil e Argentina, acompanhando a circulação internacional de tendências modernistas nas artes, nas técnicas, na arquitetura e no planejamento das cidades.

Destacam-se nesse cenário, a partir da década de 1950, a criação de estúdios e escritórios integrados por artistas, arquitetos e designers atuantes em segmentos como comunicação visual e mobiliário moderno -, a fundação de cursos e escolas especializadas e a publicação de revistas com especial interesse no desenho industrial como Habitat e Módulo, no Brasil, e nueva visión, na Argentina (AMORIM, 2015; 2019).

Essas realizações estão inseridas na experiência econômica do segundo pós-guerra na Argentina e no Brasil, a qual, de acordo com Fausto \& Devoto (2004), foi permeada por dificuldades em pontos semelhantes e por um "desenvolvimento marcado pelo "stop and go". Ambos os países alternaram "períodos de crescimento e crise, políticas expansionistas e de ajuste, com o Estado desempenhando importante papel em sua reorientação" (FAUSTO \& DEVOTO, 2004: 321). No que tange ao desenho industrial, apesar da significativa modernização tecnológica conquistada nesse período, foram limitadas as oportunidades para o desenvolvimento nacional de projetos de produtos industrializados, tanto no Brasil quanto na Argentina, visto que a importação de pacotes tecnológicos e de projetos para a montagem local e mesmo a cópia ilegal de produtos constituíam as práticas dominantes nas empresas (MÉNDEZ MOSQUERA, 1969; BRAGA, 2011; AMORIM, 2015).

Tais políticas de crescimento industrial acelerado, baseadas na ação forte do Estado e no capital estrangeiro, foram condicionantes mais imediatas que influenciaram o processo de introdução do desenho industrial no Brasil e na Argentina a partir dos anos 1950. Uma leitura histórica mais abrangente, contudo, é capaz de agregar outros elementos, dando maior nitidez à complexidade desse fenômeno. Assim, este artigo, com base nos métodos histórico e comparativo, retoma as trajetórias de formação desses dois países, do período colonial às três primeiras décadas do século XX, abordando antecedentes que também deram contorno à fase inicial do exercício do desenho industrial moderno brasileiro e argentino.

\section{A economia colonial e a gênese da indústria no Brasil e na Argentina}

De acordo com Prado Júnior (2011), a ação colonizadora na região tropical e subtropical da América a partir do século XVI, caracterizada pela exploração dos recursos naturais em função dos interesses do comércio europeu, esclarece, nas dimensões econômicas e sociais, a formação e evolução históricas dos países que ali se constituíram, mesmo considerando as especificidades das colonizações espanhola e portuguesa. Essa perspectiva explicaria a origem da ainda vigente subordinação do Brasil e da Argentina nas relações com os centros desenvolvidos internacionais. 
Segundo Furtado (2007), tal lógica produtiva de matérias-primas voltada aos mercados centrais implicou também, entre outras fragilidades, a fragmentação regional e a formação tardia de uma consciência latino-americana. Ao exportar produtos semelhantes e importar itens manufaturados de fora da região, esses países não estabeleceram vínculos comerciais entre si, alimentando uma desarticulação e ausência de sentido de comunidade que se prolongaram até meados do século XX (ZANATTA, 2012).

Repercussões negativas do modelo agroexportador podem ser percebidas ainda em setores específicos da produção colonial no Brasil relacionados à elaboração da matéria-prima. As artes e o artesanato, por exemplo, foram práticas desestimuladas em função do pacto que previa a importação e o consumo de produtos manufaturados oriundos da metrópole e de seus parceiros. De acordo com Prado Júnior, identifica-se nas zonas rurais a pequena oficina doméstica de apoio aos estabelecimentos agrícolas ou de mineração, a qual reunia serviços de carpintaria e manufaturas de tecido e de ferro, executados por escravizados. Posteriormente, nos centros urbanos, as profissões mecânicas foram mais numerosas, eventualmente organizadas em corporações, mas também dependiam da mão de obra escrava. A respeito desse sistema - vigente no Brasil desde o início da colonização, em 1531, até a abolição da escravatura, em 1888 - Vianna Filho comenta:

A sociedade branca reservara para si a função de mandar. Cruzava os braços, assistindo à labuta áspera do negro. O trabalho era o negro. Sem êle [sic] nada se poderia fazer nem pretender. [...] As menores cousas [sic], os trabalhos mais insignificantes, tudo era realizado pelo negro. Nos sobrados, nos engenhos, nos campos, tôda [sic] atividade seria absorvida pela massa escrava, importada da África, e cuja inteligência facilmente apreendia os conhecimentos necessários ao serviço para que era designada (VIANNA FILHO, 1946: 118119).

É importante ressaltar que além de explorar a força de trabalho do africano escravizado, o sistema produtivo colonial no Brasil também tirou proveito das qualificações e habilidades já desenvolvidas por esses indivíduos em seu próprio continente. Como observa Araújo (2013: 34), muitos deles trouxeram "amplo conhecimento das técnicas metalúrgicas e mineradoras, de marcenaria, de ourivesaria crioula, de plantação e colheita do café, do açúcar e da construção de máquinas de engenhos".

Contudo, numa sociedade na qual todo trabalho manual era destinado a escravizados africanos e indígenas, as atividades que exigiam a utilização das mãos ou o esforço físico eram percebidas como degradantes e envoltas em preconceito. "Por uma inversão ideológica, os ofícios mecânicos passavam a ser desprezados, como se houvesse algo de essencialmente aviltante no trabalho manual, quando a exploração do escravo é que o era" (CUNHA, 2005: 221). Em consequência, homens livres afastavam-se da prática do artesanato, no intuito de não deixar dúvidas quanto a sua condição social. Essa, inclusive, segundo Cunha (2005), foi uma das razões para que as Corporações de Ofícios no Brasil não tenham se desenvolvido como em outros países da América Latina. 
Diante de um cenário pouco favorável a atividades que não fossem voltadas à agricultura ou à mineração, funcionavam espalhadas pela colônia pequenas oficinas como olarias, para o fabrico de telhas e cerâmica, curtumes e manufaturas de cordoaria, além de outras de especialidades locais. Essas práticas rudimentares prevaleceram até o início do século XIX. Importa lembrar que contribuiu decisivamente para a longa permanência dessa condição a rigorosa política de combate à independência econômica da colônia, a qual só veio a abrandar-se a partir de 1795, com a autorização do governo para o estabelecimento das manufaturas de ferro, e com a liberação em definitivo da manufatura têxtil em 1808, em decorrência da migração forçada da família real para o Brasil (PRADO JÚNIOR, 2011).

Prado Júnior ressalta, no entanto, que, mesmo depois de livrar-se da dominação portuguesa, o Brasil não reformulou as bases de sua estrutura econômica, permanecendo ao longo do século XIX como fornecedor de insumos tropicais - notadamente de café, a partir de 1830.

De modo semelhante ao Brasil, a Argentina caracterizou-se como uma economia exportadora de produtos primários, abastecida de manufaturas importadas predominantemente de origem inglesa, concentrada na extração de minério durante o século XVIII, quando ainda pertencia ao vice-reino do Rio da Prata, e a partir do início do século XIX, na pecuária bovina e ovina e no cultivo de cereais (FAUSTO \& DEVOTO, 2004).

É importante salientar que a mão de obra escrava teve papel fundamental na economia argentina durante o período de dominação espanhola. Entre os anos de 1742 e 1806, vinte e cinco mil escravizados viviam em Buenos Aires, metade deles trazida do Brasil. De acordo com Fausto (2005), entre inúmeras funções, lá também desempenharam profissões artesanais, como sapateiros, alfaiates e ferreiros, na condição de "escravos de ganho" - com maior liberdade para transitar, mas obrigados a dar parte do rendimento do trabalho a seus senhores. Com a proibição do tráfico na Argentina em 1813 e a emancipação em 1853, a presença negra em Buenos Aires entraria em declínio, afetada também pelo enorme fluxo da imigração europeia e a miscigenação que contribuiu para o branqueamento populacional.

Nessa época, marcada por conflitos em prol da independência e posteriores guerras civis, alcançaram maior desenvolvimento os setores artesanais voltados à construção e ao mobiliário, seguidos pelos artigos de couro (RASPI, 2001). De acordo com Malatesta, só mesmo nas últimas décadas do século XIX, durante o auge da produção agropecuária, se iniciaria o processo industrial argentino, condicionado por importantes transformações políticas, econômicas e sociais ocorridas no país, tais como:

(...) o fim dos enfrentamentos armados e a vigência dos princípios constitucionais, a incorporação de terras resultantes da denominada "conquista do deserto", a federalização da cidade de Buenos Aires, o estabelecimento de uma rede de transportes, a formação de mercado interno ao eliminar-se o pagamento de direitos provinciais, o crescimento demográfico em função da chegada de grandes contingentes de imigrantes europeus e o investimento de capital externo (MALATESTA, 2002: 48).

Nesse período, constituem a maior parte da atividade industrial da Argentina os pequenos estabelecimentos artesanais de grupos familiares, detentores de baixa tecnologia e com 
capacidade para o simples aproveitamento de matérias-primas oriundas da agricultura. Em menor escala, um reduzido grupo de "empresas de envergadura" - com presença nos setores alimentício, têxtil e da construção - cresceria com o passar dos anos (MALATESTA, 2002).

É importante lembrar que em fins do século XIX o investimento na indústria ainda era escasso, principalmente se levarmos em conta que a agropecuária garantia, entre outros benefícios, alta rentabilidade em curto prazo. O pequeno empresariado que se forma nesse momento na Argentina se concentrará, portanto, em negócios seguros, com rendimentos asseverados e demanda abundante, e que em função de tais condições, como registra Malatesta (2002: 49), "não se preocupa com o progresso tecnológico, a inovação, a incorporação de técnicos e especialistas, e em síntese, com o melhoramento do produto".

Observa-se ainda a concorrência com os artigos importados - de melhor qualidade, menor preço e há muito incorporados aos hábitos dos consumidores - como outro importante fator de desestímulo às iniciativas fabris locais. E nesse campo, não foram poucas as vezes que industriais simularam a procedência europeia de seus produtos adotando rótulos, marcas e etiquetas semelhantes aos dos similares importados (MALATESTA, 2002).

\section{O cultivo da mentalidade industrial: as escolas de ofícios e a imprensa}

Apesar do escasso fomento às atividades manufatureiras desde o período colonial, a Argentina abrigaria, em 1799, a pioneira, ainda que efêmera, Academia de Geometría y Dibujo de Buenos Aires, iniciativa de Manuel Belgrano. À época Secretário do Consulado do Comércio e um dos principais incentivadores da educação e da imprensa no país, Belgrano havia fundado a Escola Náutica e a Escola de Matemática (INSTITUTO, 2013), e em 1796 já defendia em seus escritos a criação das escolas de artes e ofícios como importante meio para a instrução da população e a prevenção da miséria.

Posteriormente, integrando uma série de investimentos em educação implementados na Argentina ao longo do século XIX, foi criada em 1897 a Escuela Industrial de la Nación, com o objetivo de capacitar técnicos nas áreas de química, engenharia e mecânica, conjugando o ensino teórico e prático (BELOTTA, 2010). Entre iniciativas no campo artístico, destaca-se a abertura do Museo Nacional de Bellas Artes, em 1896.

No Brasil, é a Escola Real das Ciências, Artes e Ofícios, fundada por decreto de D. João VI em 1816 e depois batizada de Academia Imperial de Belas Artes, que irá inaugurar no país uma modalidade de ensino voltada para as relações entre arte e indústria, com o objetivo de suprir a carência de mão de obra qualificada (LEITE, 2008). Concebida por Antonio de Araújo Azevedo, o conde da Barca, seu projeto inicial previa o ensino artístico através de oficinas. Em 1855, foi reformada pelo então diretor, o pintor e poeta Araújo Porto-Alegre, passando a oferecer também um curso noturno para alunos artífices, do qual fazia parte a disciplina "desenho industrial" (desenho técnico aplicado a fins práticos), o que denota o uso desse termo no Brasil desde essa época (CARDOSO, 2004; 2005).

Em 1827, no Rio de Janeiro, foi fundada a Sociedade Auxiliadora da Indústria Nacional. Seu objetivo era promover a prosperidade da indústria no Império do Brasil, e mais especificamente 
ao desenvolvimento de técnicas e equipamentos para a produção agrícola. Entre 1833 e 1892, a Sociedade publicou a revista mensal O Auxiliador da Indústria Nacional. De acordo com Barreto, o periódico, "cuja difusão extrapolou a Corte, acompanhou os progressos científicos e tecnológicos inerentes à Revolução Industrial, divulgando a adoção da máquina a vapor e a mecanização do trabalho como condição para o progresso" (BARRETO, 2008). Em 1861, a Sociedade promoveria ainda a Primeira Exposição da Indústria Nacional, mostra que serviu de ensaio para a participação do país no ano seguinte na Exposição Universal de Londres [Great London Exposition].

A partir de 1864, no Brasil, surgiram também as escolas de Arts et Métiers e os liceus de Artes e Ofícios no Rio de Janeiro (1858), Bahia (1872) e São Paulo (1873). De acordo com Leite (2008), essas instituições promoveram o desenvolvimento dos ofícios manuais e das qualidades exigidas para a projetação dessas atividades.

Em 1818, foi criado o Museu Real, depois convertido em Museu Nacional da Quinta da Boa Vista, abrindo caminho aos primeiros acervos de cultura do país. A atividade tipográfica, com a fundação da Imprensa Régia em 1808, foi finalmente autorizada no Brasil, registrando-se posteriormente, ao final do século XIX, uma significativa produção de jornais, revista, livros e demais peças gráficas.

O tema da imprensa é um dos aspectos de clara distinção entre as políticas de colonização das coroas espanhola e portuguesa. No caso do Brasil, o impedimento à confecção de impressos ao longo de três séculos - decorrendo daí sérios entraves ao desenvolvimento da educação e da cultura intelectual na colônia - refletiu o firme propósito da administração lusitana de inviabilizar a circulação de ideias que pudessem ameaçar a estabilidade de seu domínio (CAMARGO, 2003).

Na Argentina, a introdução da imprensa ocorreu pelo menos cinquenta anos antes de sua prática outorgada no Brasil. A Companhia de Jesus instalou na cidade de Córdoba, em 1758, uma tipografia para auxílio no catecismo dos indígenas, sendo depois transferida para Buenos Aires, onde passou a funcionar sob o nome de Real Imprenta de Niños Expósitos, a partir de 1780 (ARGENTINA, 2013). É importante notar, contudo, que a Argentina foi uma das últimas colônias espanholas a incorporar a imprensa, levando-se em conta o estabelecimento da primeira oficina tipográfica das Américas na Cidade do México, em 1539, e a consequente disseminação da técnica no Peru (1542), na Guatemala (1660), em Cuba (1720), na Colômbia (1738) e no Chile (1776) (CAMARGO, 2003).

\section{Forjando cidades: crescimento demográfico e infraestrutura}

Em relação à composição étnica dos dois países, identifica-se que, em finais dos século XIX, $42 \%$ da população brasileira era de mestiços, $38 \%$ de brancos e $20 \%$ de negros, aparecendo na Argentina o componente branco em bem maior número, independentemente da presença de negros, indígenas e mestiços, característica que só tenderia a crescer com o ciclo da imigração transatlântica a partir de 1870 (FAUSTO \& DEVOTO, 2004).

Para governantes argentinos, em meados do século XIX, a imigração europeia introduziria hábitos de trabalho e consumo modernos, tornando-se exemplo para a população nativa. $\mathrm{O}$ 
comentário de Malatesta, a seguir, corrobora essa ideia, ao descrever a participação dos imigrantes na incipiente indústria argentina daquele período:

(...) não são poucos os estrangeiros fixados em terras argentinas que com espírito empreendedor investem capital considerável em seus estabelecimentos fabris e aplicam técnicas e experiências adquiridas em seus países de origem. Dessa forma, os imigrantes do exterior se inserem na atividade industrial não só no estrato obreiro, mas também garantem presença significativa entre os proprietários (MALATESTA, 2002: 48).

Alvo de intenso crescimento urbano entre 1895 e 1914, a Argentina experimentou relevante desenvolvimento não só em Buenos Aires, capital federal desde 1880, mas em áreas como Rosário, Mendoza e Tucumán. Outro dado significativo do ano de 1895 é que 27,1\% da população do país já vivia em cidades, e a Grande Buenos Aires contava com mais de 100 mil habitantes. Ali se constituiu um agrupamento populacional socialmente complexo, com a presença de novos quadros de elite e amplos setores de trabalhadores, o que levou à formação de uma classe média urbana de considerável importância (MALATESTA, 2002).

O Brasil, entretanto, permanecia como um país maciçamente rural e de população dispersa, da qual, no ano de 1890, apenas 10,9\% viviam em cidades. Dentre essas áreas, o Rio de Janeiro, capital do Império, projetou-se com impressionantes taxas de crescimento populacional, chegando a 300 mil habitantes na década de 1880. Diante das implicações sociais e de infraestrutura decorrentes dessa expansão, a ordenação do espaço público tornou-se prioritária. Melhorias começaram a ser implementadas desde a segunda metade do século XIX, sendo realizada a primeira reforma urbana na cidade entre 1902 e 1906, com o aterramento de trechos do litoral, desmonte de morros e abertura de largas avenidas. Através de concessões públicas, empresas privadas estrangeiras foram responsáveis pela execução desses e de outros serviços e reformas urbanas, "o que significava que também a tecnologia e os projetos vinham todos de fora, envolvendo pouca ou nenhuma transferência de capacidade produtiva para o solo brasileiro" (CARDOSO, 2004: 59). Sem falar na posterior remessa para a Europa dos lucros oriundos desses investimentos, prática igualmente observada na Argentina.

São Paulo, por sua vez, logrou notório progresso a partir dos anos 1890, devido ao crescimento urbano viabilizado pelo influxo de imigrantes $-54 \%$ de sua população era formada por italianos em 1893 - e da concentração de negócios ligados ao café (CARDOSO, 2004). Beneficiada por estradas de ferro e de rodagem com acesso ao porto de Santos, São Paulo, cuja primeira iluminação elétrica estável foi implantada em 1891, dispunha ainda de excelente localização geográfica para a articulação de relações comerciais dentro e fora do país (LOPEZ \& MOTA, 2008).

Entretanto, Argentina e Brasil não dispunham do capital e dos recursos técnicos para essas e outras transformações infraestruturais. De acordo com Williamson (2012), a riqueza acumulada através do comércio internacional era destinada ao consumo de luxos e meios de prestígio social, à moda das aristocracias proprietárias de terras. Assim, a viabilização de subsídios para obras públicas e desenvolvimento técnico e industrial eram deixados a cargo de capitalistas estrangeiros, de empresários imigrantes ou do Estado. Dentre esse reduzido grupo de investidores, a Grã- 
Bretanha assumiu posição crucial na estrutura interna das economias argentina e brasileira, principalmente até a Primeira Guerra, quando perderia a hegemonia internacional para os Estados Unidos (WILLIAMSON, 2012).

\section{Dos 1900 aos turbulentos anos 1930: crises e revoluções}

Desde a segunda metade do século XIX, as relações entre Brasil e Argentina caracterizavamse por uma velada rivalidade - com origens que remetiam à disputa pela posse da Província Cisplatina -, alimentada pelo ideal de liderança na região. Nesse cenário, verifica-se a aproximação do Brasil aos Estados Unidos, visando, entre outros objetivos, a ampliação de sua influência sobre os países vizinhos na América do Sul. A Argentina concentrou-se nas longevas relações com a Inglaterra e a Alemanha (LOPEZ \& MOTA, 2008).

No campo da política argentina, o impulso progressista manifestou-se mais precisamente através da experiência democrática, ainda que "jovem e imperfeita", refletida no surgimento de sindicatos e partidos políticos, e na introdução do voto masculino, secreto e obrigatório, a partir da Lei Sáenz Peña, de 1912. Também destaca-se nesse período a presidência de Hipólito Yrigoyen (1916-1922) e sua posterior reeleição (1928-1930), cujo projeto de "'reparação nacional' representou uma política de nacionalismo econômico e de combate às oligarquias" (AQUINO et al, 2010, p.618). Sob seu comando foram aprovadas leis sociais por melhores condições de trabalho e salário, promoveu-se a expansão do crédito bancário à indústria e à agricultura e criouse a Yacimientos Petrolíferos Fiscales (YPF), em 1922, para a exploração do petróleo argentino.

Em discordância com as classes conservadoras e o exército, o governo de Yrigoyen, classificado como personalista e paternalista por seus opositores, fragilizou- se ainda mais com a crise internacional do capitalismo de 1929 e seus efeitos sobre a pecuária e a indústria frigorífica. Em 1930, enfim, um golpe de Estado liderado pelo general José Félix Uriburu interrompeu a sucessão constitucional de ordem presidencial na Argentina pela primeira vez desde 1862 (TERÁN, 2012). Nesse momento, deu-se início aos governos da Concordância (1932-1943), capitaneados por uma coligação de conservadores e radicais anti-Yrigoyen.

Esses anos ficariam conhecidos como La Década Infame (1930-1943), cingidos pela prática sistemática da fraude eleitoral, pela corrupção instalada nas esferas estatais, pelo desemprego e pelo predomínio de grupos oligarcas, fascistas e inclinados à cessão de privilégios ao capital estrangeiro, preferencialmente ao britânico (TERÁN, 2012). Mais adiante, com um novo movimento militar em 1943, instaurou-se uma nova etapa na vida política do país, abrindo caminho à ascensão de Juan Domingo Perón à presidência em 1946.

O Brasil permaneceu atrelado às limitações não superadas durante a transição do Império para o regime republicano: "a herança colonial, a condição periférica, o atraso estrutural e multissecular"(LOPEZ \& MOTA, 2008, p. 551).

Construída em moldes conservadores, a República Velha, inaugurada pelo golpe militar que derrubou D. Pedro II em 1889, primou pela exclusão política e sociocultural - apenas 5\% da população tinham direito de voto e nas classes inferiores o analfabetismo era de quase $100 \%$. Seus 
principais eixos de sustentação foram a alternância regular de poder entre as oligarquias mais ricas - São Paulo e Minas Gerais - e o café, cuja produção ganhou impulso renovado com o investimento inglês e a mão de obra imigrante. A hegemonia econômica dos cafeicultores paulistas, entretanto, não se sustentaria sem gerar intensos conflitos políticos e sociais.

Entre convulsões que marcaram a época, guerras internas, como a de Canudos, e revoltas, como as dos Tenentes em 1922, 1924, 1926 e 1930, refletiram as frustrações de vários setores da sociedade. Some-se a isso a crise econômica de 1929, que no país também coletou seus dividendos, potencializando o impacto da iminente Revolução de 1930. Assim, apenas um mês depois do já mencionado golpe militar que depôs Hipólito Yrigoyen, na Argentina, um movimento armado liderado pelos estados de Minas Gerais, Paraíba e Rio Grande do Sul derrubou o presidente Washington Luís em 24 de outubro de 1930, impedindo a posse do presidente eleito Júlio Prestes e pondo fim à República Velha no Brasil e à hegemonia dos interesses paulistas do café.

A Nova República iniciou-se com Getúlio Vargas governando o país de forma constitucional até 1937. Adepto da centralização política e do nacionalismo econômico, Vargas defendeu o crescimento do papel do estado na promoção da indústria- de mineração, petrolífera, química, do aço, da eletricidade e da aviação - e na proteção do mercado interno. Com preocupação reformista direcionada aos assalariados urbanos, buscou atrair à sua ideologia os setores médios e populares, os quais localizavam-se no centro do cenário político das grandes cidades, onde cresciam a indústria e os serviços. Em 1930, criou o Ministério do Trabalho, Indústria e Comércio e em seguida outras instituições com atuação no âmbito das questões trabalhistas e na organização do sistema previdenciário (LOPEZ \& MOTA, 2008). Em 1933, cria o Ministério da Educação e da Saúde e em 1938 promove a estatização do gás e do petróleo nacionais (CAVALCANTI, 2006).

Opositor da democracia liberal e do pluralismo, recorreu à repressão e, em 1937, impôs o Estado Novo e o centralismo antifederalista, como observa Zanatta:

\footnotetext{
Vargas fechou o Congresso, silenciou a oposição, censurou a imprensa, recorreu sem hesitação à tortura e ao encarceramento e, diante do estalar da guerra, não ocultou sua admiração por Hitler e Mussolini, fortes no Brasil devido aos inúmeros conterrâneos instalados ali (ZANATTA, 2012: p.129).
}

Foi exatamente nessa crispada situação sociopolítica e econômica das décadas de 1920 e 1930 - instalada não apenas na Argentina e no Brasil, mas em âmbito mundial - que ocorreu o trânsito internacional de ideias modernistas e suas reverberações na arquitetura e no desenho industrial. Em Buenos Aires, arquitetos como Raul Prebisch, Ernesto Vautier e Wladimiro Acosta reivindicavam a tecnologia e o maquinismo do planejamento urbano à habitação. A escritora e editora argentina Victoria Ocampo, por sua vez, projeta e constrói, no final da década de 1920, a primeira casa moderna naquela cidade (SARLO, 2010). No Brasil, Gregori Warchavchik dá um novo sentido ao anseio modernista do arquiteto integral, ao assumir as funções de engenheiro, 
desenhista industrial e mestre de oficina, assumindo o projeto de interiores e de instalações de suas obras (mobiliário, esquadrias, luminárias, maçanetas, etc) (AMORIM, 2015). Outra experiência pioneira na racionalização do desenho e da produção de móveis no país naquele período foi a Cama Patente, criada em 1915 pelo imigrante espanhol Celso Martinez Carrera. Esse design notabilizou-se como um manifesto a favor da modernidade e da funcionalidade do móvel, trazendo "alterações profundas em termos de projeto, da execução, dos processos construtivos, da comercialização, do consumo e dos padrões do gosto no setor" (SANTOS, 2015: p.55).

\section{Desenvolvimento a passos lentos: educação e indústria}

Devido à Primeira Guerra (1914-1918), os países industrializados deixaram de fornecer seus artigos manufaturados aos agrário-exportadores, o que contribuiu para gerar condições de crescimento a algumas indústrias locais e a conquista de mercado interno. Mais adiante, no final dos anos 1920, com a quebra da bolsa de Nova York, surgiu uma nova oportunidade para indústrias no Brasil e na Argentina. Com a produção industrial estrangeira reduzida pela metade e a queda do preço dos produtos primários - o que no caso do Brasil provocou nova e violenta desvalorização do café - as indústrias nacionais tiveram que desenvolver-se, dada a impossibilidade de importação de produtos manufaturados.

Ao analisar esse contexto de industrialização induzida pela substituição de importações, Furtado apresenta dois tópicos para reflexão. O primeiro diz respeito ao modo pouco estratégico com que esforços para o desenvolvimento industrial foram empreendidos na Argentina e no Brasil. Segundo o economista, a intensificação da industrialização poderia ter acontecido antes, caso políticas adequadas houvessem beneficiado esses países, modificando a estrutura do núcleo industrial. Na ausência desses estímulos, esses setores acabaram entrando em depressão e só mais adiante, com o incentivo da ação estatal às indústrias de base, se faria avançar o processo de industrialização latino-americano (FURTADO, 2007).

O segundo ponto levantado por Furtado salienta a prejudicial dependência financeira e tecnológica de países como Argentina e Brasil, decorrente das facilidades de obtenção de financiamento no exterior para investimentos industriais, visto que tais aportes implicavam a aquisição de tecnologia e equipamentos oriundos dos centros internacionais.

Assim, ambos os países permaneciam na condição de coadjuvantes em relação ao seu próprio desenvolvimento, o qual continuava a ser pautado por interesses externos. Realizada nesses termos, a instalação de indústrias na Argentina e no Brasil prescindia da preparação de quadros locais com efetivo conhecimento dos processos tecnológicos. O que comprometeria, em médio prazo, tanto a autonomia quanto o fomento de uma mentalidade industrial nesses países, e, em última instância, a inserção e consolidação do desenho industrial nessa região.

\section{Conclusões}

Apesar do desenvolvimento econômico e da crescente complexidade da vida urbana, ambos os países seguiram no papel de exportadores de matérias-primas, consumidores de produtos manufaturados estrangeiros e dependentes de investimentos adventícios. Mesmo depois de 
convertidas em Repúblicas Federativas - a Argentina em 1816 e o Brasil em 1889 -, não havia novas classes no poder e as estruturas oligárquicas da era colonial pouco se alteraram, salvo a incorporação de alguns valores liberais como o mercado livre. De toda forma, a virada para o século XX lhes reservou períodos de avanço econômico e significativa modernização cultural, ainda que acompanhados de pesadas cotas de instabilidade político-social e financeira. Cenário que, cinco décadas depois, seria o palco para o desenvolvimento do design moderno como nova prática profissional, tanto no Brasil quanto na Argentina.

\section{Referências}

AQUINO, Rubim et al. História das sociedades modernas às sociedades atuais. Rio de Janeiro: Imperial Novo Milênio, 2010.

AMORIM, Patricia. Cruzadas editoriais no Brasil e na Argentina: o desenho industrial na perspectiva das revistas Habitat e Mirante das Artes, \&tc, nueva visión e Summa [1950-1969]. Tese de doutorado. Departamento de Design. Universidade Federal de Pernambuco. Recife, 2015.

AMORIM, Patricia; CAVALCANTI, Virginia. O desenho industrial no Brasil e na Argentina (1950-1969): a perspectiva das revistas Habitat e Mirante das Artes,\&tc, nueva visión e Summa. ESTUDOS EM DESIGN (ONLINE), v. 27, 2019.

ARAÚJO, Emanuel. Arte, adorno, design e tecnologia no tempo da escravidão. São Paulo: Museu Afro Brasil, 2013.

ARGENTINA.GOV.AR. Guía del estado. Información. Cultura. Prensa escrita, historia y presente. Disponível em: http://www.argentina.gob.ar/informacion/cultura/110prensa-escrita-historia-y-presente.php. Acesso em: 8 de jul. 2013.

BARRETO, Patrícia. Sociedade Auxiliadora da Indústria Nacional: oficina de homens. XIII ENCONTRO DE HISTÓRIA ANPUH-RIO IDENTIDADES. ago. 2008.

BELOTTA, Araceli. Artes y Oficios en la Argentina. Dos siglos de trabajo nacional. Acción Mayorista, Buenos Aires, n. 132, mai. 2010.

BRAGA, Marcos. ABDI e APDINS-RJ: história das associações pioneiras de design no Brasil. São Paulo: Blucher Acadêmico, 2011.

CAMARGO, Mário. Gráfica: arte e indústria no Brasil: 180 anos de história. São Paulo: Bandeirantes, 2003.

CARDOSO, Rafael. Uma introdução à história do design. São Paulo: Blucher, 2004.

O design brasileiro antes do design: aspectos da história gráfica, 1870-1960. São Paulo: Cosac Naify, 2005.

CAVALCANTI, Lauro. Moderno e brasileiro: a história de uma nova linguagem na arquitetura. Rio de Janeiro: Jorge Zahar, 2006.

CUNHA, Luiz Antônio. O ensino de ofícios artesanais e manufatureiros no Brasil escravocrata. São Paulo: UNESP; Brasília, DF: FLACSO, 2005. (ebook).

FAUSTO, Boris. Não existem negros em Buenos Aires. In: Memória e história. São Paulo: Graal, 2005.

; DEVOTO, Fernando. Brasil e Argentina: um ensaio de história comparada (18502002). São Paulo: Ed. 34, 2004.

FURTADO, Celso. A economia latino-americana: formação histórica e problemas contemporâneos. São Paulo: Companhia das letras, 2007. 
INSTITUTO Nacional Belgraniano. Belgrano y la Academia de Dibujo. Disponível em: http://www.manuelbelgrano.gov.ar/belgrano_y_dibujo.htm. Acesso em: 25 de jan. 2013.

LEITE, João de Souza. De costas para o Brasil: o ensino de um design internacionalista. In: MELO, Chico Homem de (org.). O design gráfico brasileiro: anos 60. São Paulo: Cosac Naify, 2008.

LOPEZ, Adriana; MOTA, Carlos. História do Brasil: uma interpretação. São Paulo: Senac São Paulo, 2008.

MALATESTA, Alicia. Notas para la historia de la indústria argentina (primera parte). Tecnológica, Universidad \& Empresa $-T U \& E$, Buenos Aires, Editorial Universitaria de la U.T.N., 2002, n.23. Disponível em: http://www.edutecne.utn.edu.ar/historiaindustria/hist-ind1.pdf. Acesso em: 25 de jan. 2013.

MELO, Chico; RAMOS, Elaine. Linha do tempo do design gráfico no Brasil. São Paulo: Cosac Naify, 2011.

MÉNDEZ MOSQUERA, Lala. Editorial. SUMMA, Buenos Aires, n. 15, fev. 1969.

PRADO JÚNIOR, Caio. Formação do Brasil contemporâneo: colônia. São Paulo: Companhia das Letras, 2011.

RASPI, Emma. El mundo artesanal de dos ciudades del norte argentino. Salta y Jujuy, primera mitad del siglo XIX. Anuário de Estudios Americanos, Sevilha, Escuela de Estudios Hispano-Americanos, Tomo LVIII, 2001, n.1. Disponível em: http://estudiosamericanos.revistas.csic.es/index.php/estudiosamericanos/article/view/23 2/236. Acesso em: 27 de jan. 2013.

SANTOS, Maria Cecilia Loschiavo dos. Móvel moderno no Brasil. São Paulo: Olhares, 2015.

SARLO, Beatriz. Modernidade periférica: Buenos Aires 1920 e 1930. São Paulo: Cosac Naify, 2010.

TERÁN, Oscar. Historia de las ideas en la Argentina: diez leciones iniciales, 18101980. Buenos Aires: Siglo Veintiuno, 2012.

VIANNA FILHO, Luiz. O negro na Bahia. São Paulo: José Olympio, 1946.

WILLIAMSON, Edwin. História da América Latina. Lisboa: Edições 70, 2012.

ZANATTA, Loris. Historia de América Latina. De la Colonia al siglo XXI. Buenos Aires: Siglo Veintiuno, 2012.

\section{Sobre a autora}

Patricia Amorim é professora e pesquisadora na ESPM-SP e na FAU USP. É graduada em Jornalismo (UFPE), em Design Gráfico (IFPE) e é mestra e doutora em Design (UFPE). Em sua tese, com foco na História do Design, investigou a introdução do design moderno no Brasil e na Argentina nos anos 1950 e 1960 na perspectiva de revistas culturais. Tem interesse nos temas relacionados à história do design, meio ambiente e desigualdades sociais. pat.amorim@gmail.com 